OPEN ACCESS

Edited by:

Manuel Acosta,

University of Murcia, Spain

Reviewed by:

Jose Luis Cenis,

IMIDA, Spain

Jer-Chia Chang,

National Chung Hsing University,

Taiwan

*Correspondence:

Rodrigo Infante

rinfante@uchile.c

Specialty section

This article was submitted to Plant Genetics and Genomics,

a section of the journal

Frontiers in Plant Science

Received: 27 January 2017

Accepted: 20 March 2017

Published: 11 April 2017

Citation:

Salazar JA, Pacheco I, Shinya P.

Zapata P, Silva C, Aradhya M,

Velasco $D$, Ruiz $D$, Martínez-Gómez $P$ and Infante $R$ (2017) Genotyping by

Sequencing for SNP-Based Linkage Analysis and Identification of QTLS Linked to Fruit Quality Traits in

Japanese Plum (Prunus salicina Lindl.). Front. Plant Sci. 8:476.

doi: 10.3389/fp/s.2017.00476

\section{Genotyping by Sequencing for SNP-Based Linkage Analysis and Identification of QTLs Linked to Fruit Quality Traits in Japanese Plum (Prunus salicina Lindl.)}

\author{
Juan A. Salazar ${ }^{1}$, Igor Pacheco ${ }^{2}$, Paulina Shinya ${ }^{1}$, Patricio Zapata ${ }^{1}$, Claudia Silva ${ }^{2}$, \\ Mallikarjuna Aradhya ${ }^{3}$, Dianne Velasco ${ }^{4}$, David Ruiz ${ }^{3}$, Pedro Martínez-Gómez ${ }^{4}$ and \\ Rodrigo Infante ${ }^{1 *}$
}

${ }^{1}$ Departamento de Producción Agrícola, Universidad de Chile, Santiago, Chile, ${ }^{2}$ Laboratorio de Bioinformática y Expresión Génica, Instituto de Nutrición y Tecnología de Alimentos, Universidad de Chile, Santiago, Chile, ${ }^{3}$ National Clonal Germplasm Repository, ARS, USDA, Davis, CA, USA, ${ }^{4}$ Departamento de Mejora Vegetal, CEBAS-CSIC, Murcia, Spain

Marker-assisted selection (MAS) in stone fruit (Prunus species) breeding is currently difficult to achieve due to the polygenic nature of the most relevant agronomic traits linked to fruit quality. Genotyping by sequencing (GBS), however, provides a large quantity of useful data suitable for fine mapping using Single Nucleotide Polymorphisms (SNPs) from a reference genome. In this study, GBS was used to genotype 272 seedlings of three F1 Japanese plum (Prunus salicina Lindl) progenies derived from crossing "98-99" (as a common female parent) with "Angeleno," "September King," and "September Queen" as male parents. Raw sequences were aligned to the Peach genome v1, and 42,909 filtered SNPs were obtained after sequence alignment. In addition, 153 seedlings from the "98-99" × "Angeleno" cross were used to develop a genetic map for each parent. A total of 981 SNPs were mapped (479 for "98-99" and 502 for "Angeleno"), covering a genetic distance of 688.8 and $647.03 \mathrm{cM}$, respectively. Fifty five seedlings from this progeny were phenotyped for different fruit quality traits including ripening time, fruit weight, fruit shape, chlorophyll index, skin color, flesh color, over color, firmness, and soluble solids content in the years 2015 and 2016. Linkage-based QTL analysis allowed the identification of genomic regions significantly associated with ripening time (LG4 of both parents and both phenotyping years), fruit skin color (LG3 and LG4 of both parents and both years), chlorophyll degradation index (LG3 of both parents in 2015) and fruit weight (LG7 of both parents in 2016). These results represent a promising situation for GBS in the identification of SNP variants associated to fruit quality traits, potentially applicable in breeding programs through MAS, in a highly heterozygous crop species such as Japanese plum.

Keywords: Japanese plum, breeding, fruit quality, molecular markers, ripening, Prunus salicina, SNP, GBS 


\section{INTRODUCTION}

Japanese plum (Prunus salicina Lindl.) is a crop tree species native to China. It has a diploid genome $(2 n=2 x=16)$, unlike the European plum ( $P$. domestica L.), which has a hexaploid genome $(6 n=2 x=48)$, although both species belong to the Rosaceae family, subfamily Prunoideae, genus Prunus, and subgenus Prunophora (Topp et al., 2012). Plums, including Japanese plum and European plum, with a production of 11.52 million tons (Mt) in 2015, are the second stone fruit production after peaches and nectarines (annual production of $21.63 \mathrm{Mt}$ ). China is by far the world leading producer of plums $(5.90$ $\mathrm{Mt}$ ) based on Japanese plums. Another major Japanese plumproducing area includes the European countries bordering the Mediterranean Sea, mainly Spain $(0.21 \mathrm{Mt})$, France $(0.20 \mathrm{Mt})$, and Italy $(0.19 \mathrm{Mt})$. USA is another major plum producer $(0.24$ $\mathrm{Mt}$ ) for European and Japanese plums, and the most important exporting country of dried plums. In the Southern hemisphere plum production is dominated by Chile $(0.30 \mathrm{Mt})$ followed by Argentina $(0.15 \mathrm{Mt})$, also based on Japanese plum production (http://faostat.fao.org).

Most commercial Japanese plum production is, however, based on a few cultivars, and it is therefore necessary to diversify the range of varieties to accelerate breeding programs. The most advanced breeding programs of this species are in California (Okie and Ramming, 1999), although important programs are currently being developed in China, South Africa, Spain, Italy, Brazil, and Chile (Hartmann and Neumüller, 2009; Topp et al., 2012; Liu et al., 2013; Ruiz et al., 2016).

Marker-assisted selection (MAS) is an important biotechnological tool used in Prunus breeding programs to improve the efficiency of developing new genotypes, although its use is currently limited to traits with a low number of genes involved in their expression (Salazar et al., 2014). The polygenic nature of most of the useful traits (mainly related to fruit quality), with genes distributed throughout the entire genome, makes it very difficult to develop linked markers. Many authors have therefore focused on the study and characterization of these polygenic traits in different Prunus species from both a phenological point of view (Campoy et al., 2010; Dirlewanger et al., 2012; Socquet-Juglard et al., 2013; Castède et al., 2015; Eduardo et al., 2015; Nuñez-Lillo et al., 2015; Salazar et al., 2016), a pomological perspective (Sooriyapathirana et al., 2010; Zhang et al., 2010; Rosyara et al., 2013; Salazar et al., 2013; Da Silva Linge et al., 2015; Fresnedo-Ramírez et al., 2015, 2016; Lambert et al., 2016; Zeballos et al., 2016) and regarding pathogen resistance issues (Martínez-García et al., 2013a; Yang et al., 2013; Pacheco et al., 2014). These studies have been focused on the identification of QTLs in peach $[P$. persica (L.) Batsch] $(2 n=2 x$ $=16)$; sweet cherry (P. avium L. $)(2 n=2 x=16)$; and apricot $(P$. armeniaca L.) $(2 n=2 x=16)$.

In the case of Japanese plum, however, only a few researches have been focused to QTL identification. For example some studies are aimed for identifying QTLs linked to nematode [Meloidogine incognita Kofoid et White and Meloidogine arenaria (Neal) Chitwood] resistance using plum progenies and interspecific plum $\times$ almond $[$ P. amygdalus (Batsch) syn. P. dulcis
(Miller) Webb] $(2 n=2 x=16) \times$ peach progenies (Claverie et al., 2004; Dirlewanger et al., 2004a; Van Ghelder et al., 2010). As far as we know, the QTL analysis of traits linked to fruit quality has not yet been done in P. salicina. More studies focused on this species are therefore needed in order to incorporate MAS into the new breeding programs for P. salicina fruit quality.

In recent years it has become increasingly common to use SNP markers to get sutured genetic maps for greater accurate QTL identification using different techniques as Fresnedo-Ramírez et al. (2016) and Zeballos et al. (2016) which have been mapping 2,398 and 8,144 SNP markers respectively using IPSC 9K peach SNP array (Verde, 2012) identifying several QTLs for fruit quality traits in peach or Lambert et al. (2016) which identified major genes for fruit flesh color $(Y)$, skin pubescence $(G)$, stone adhesion-flesh texture (F-M), sub-acid fruit (D), and fruit shape (S) while Salazar et al. (2016) in apricot, using SNPlex technology identified significant QTLs for phenology traits especially for ripening time.

Lately, genotyping by sequencing (GBS) technology makes it possible to generate more saturated genetic maps, thus facilitating more accurate QTL identification. This next generation technology makes it possible to build libraries of thousands of DNA fragments (tags), as has been done in maize (IBM) and barley (Oregon Wolfe Barley), for which 200,000 and 25,000 sequence tags, respectively, have been mapped. A single GBS experiment can provide 25,000 SNPs, which can be used for germplasm characterization, plant breeding progeny studies and QTL mapping (Bielenberg et al., 2015; Guajardo et al., 2015).

GBS technology provides large quantities of quality data that can be used for fine mapping, identification of SNP markers from a reference genome and localization of QTLs for certain quality traits of interest linked to specific genes. GBS is a highthroughput technique that has been widely applied in different species for multiple purposes, including for heritability studies (Ashraf et al., 2016); diversity analysis in maize and barley (Elshire et al., 2011); population structure evaluation in Cassava (Rabbi et al., 2015); and genetic structure analysis in Poaceae (McAllister and Miller, 2016). The technology has also been used for seed characterization in chickpea (Verma et al., 2015) and for the identification of QTLs linked to different traits like preharvest sprouting and rust resistance in wheat (Lin et al., 2015; Bajgain et al., 2016) and club root resistance in cabbage (Lee et al., 2015). In fruit species, GBS has been used to identify QTLs linked to blooming date and low temperature requirements in peach (Bielenberg et al., 2015). GBS does not enable us to generate molecular markers for MAS (Yang et al., 2016), but it does make it possible to more precisely localize QTLs in order to perform deeper sequencing and generate effective molecular tools for MAS. The GBS technology could therefore be particularly useful in species such as Japanese plum and for studying traits like fruit quality traits, i.e., in cases where the molecular information is limited.

The objective of this work was to generate a saturated genetic map in $P$. salicina and to carry out the QTL identification of several important fruit quality traits in order to locate major QTLs and associated markers to help develop MAS strategies in breeding programs. 


\section{MATERIALS AND METHODS}

\section{Plant Materials}

The plant material assayed included 11 Japanese plum cultivars and 3 F1 progenies. The F1 Japanese plum progenies (272 seedlings) were generated in the Rinconada de Maipu Experimental Station (Santiago, Chile) in 2011 by bumble bee pollination under a fine plastic mesh cage using a common female parent genotype "98-99" and three different pollen donors, including "September King," "September Queen," and "Angeleno." The "98-99" genotype is a mid-early maturing selection with red skin and yellow flesh and with high organoleptic quality. "Angeleno" is a mid-late maturing cultivar with purple skin color and excellent postharvest performance, while "September King" and "September Queen" are both very late maturing genotypes.

\section{Fruit Quality Evaluation}

Fifty-five seedlings from the "98-99" × “Angeleno" progeny were phenotyped in the years 2015 and 2016. Nine agronomic traits linked to fruit quality were evaluated including ripening time (RT), fruit weight (FW), shape (SHP), skin color (SKC), flesh color (FLSC), over color (OVC), chlorophyll index $\left(\mathrm{I}_{\mathrm{AD}}\right)$, firmness (FIRM), and the soluble solids concentration (SSC). RT was calculated in Julian days and FW in grams. SHP and fruit color (SKC, FLSC, and OVC) were visually determined and classified in numerical categories. SHP was defined according to the following scale: elongated (1), hearted (2), spherical (3), or oblate (4), while SKC was classified as green (1), yellow (2), red (3), purple (4), or black (5). FLSC was classified as white (1), green (2), yellow (3), or red (4). In addition, OVC was determined on a scale of 1-4, determined as percentages of color covering the fruit: $25 \%$ (1), $50 \%$ (2), $75 \%$ (3), and $100 \%$ (4). On the other hand, FIRM was quantified in Newton $(\mathrm{N})$ by a texture analyzer (TA.XT plus, Texture Technologies, Hamilton, MA, USA) using a $7.9 \mathrm{~mm}$ diameter plunger, and SSC was determined using an ATAGO $^{\circledR}$ hand-held refractometer calibrated as the percentage of sucrose at $20^{\circ} \mathrm{C}$. $\mathrm{I}_{\mathrm{AD}}$ chlorophyll content-related maturity index was measured by DA-meter (Gottardi et al., 2009; Infante et al., 2011a). All traits were evaluated at the harvest date, which was determined according to Contador et al. (2016), i.e., when $\mathrm{I}_{\mathrm{AD}}$ was between 1 and 1.4 units and the texture close to $40 \mathrm{~N}$. $\mathrm{I}_{\mathrm{AD}}$, FIRM, and SSC were evaluated in two maturity states: at the harvest date (1, giving place to IAD_1, FIRM_1 and SSS_1) and 1 week after harvest (2, giving place to $\mathrm{I}_{\mathrm{AD} \_2}$, FIRM_2, and SSC_2).

\section{Fruit Quality Data Analysis}

Descriptive tables and histograms showing the distribution of the proportion of seedlings were generated for each trait and year. The normality of the data was analyzed using the \$Shapiro-Wilks test, and traits showing normal distribution were analyzed by ANOVA, considering genotype and year as independent factors. Traits that did not meet the normality criteria were analyzed with the Kruskal-Wallis non-parametric test. In addition, correlations between and within traits for each year were analyzed using Pearson coefficients, and a Generalized Linear Mixed Model (GLMM) using Restricted Maximum Likehood (REML) was calculated for determining the genetic effect of each seedling by Best Linear Unbiased Predictors (BLUPs), considering the genotype factor as a random effect. All analyses and histograms were calculated and edited using INFOSTAT v16 software with the exception of the GLMM analysis, which was calculated using an interface between INFOSTAT and R.

\section{DNA Extraction and Genotyping by Sequencing (GBS)}

Young leaves for each individual were collected and lyophilized for DNA extraction, which was carried out according to the CTAB procedure described by Doyle and Doyle (1987). A total of 283 DNA samples (the 272 seedlings from the three F1 Japanese plum progenies derived from crossing "98-99" as a common female parent with "Angeleno," "September King," and "September Queen" as male parents; and the 11 Japanese plum cultivars) were sent to the Biotechnology Resource Center (BRC) at Cornell University (New York, USA). Here, Genotype by Sequencing (GBS) technology was used to generate DNA fragment libraries from each offspring and parent. The GBS analysis pipeline (Tassel v.3.0.166) was run on these samples, which were digested with the enzyme ApeKI. This enzyme is partially methylation sensitive and has been successfully used in maize (Elshire et al., 2011). The results include FASTQ files (raw sequences); TOPM files (tags on a physical map), which contain unique tag sequences of $64 \mathrm{bp}$ that were present across all samples and tag alignment information; Hapmap files, which include the SNP-calling output from the GBS bioinformatics pipeline; and VCF files (an alternative format for holding SNPs). Three lanes, one lane per plate, were used to generate the FASTQ files. Failed samples (non-blank) were defined as those with $<10 \%$ of the mean reads per sample coming from the lane on which they were sequenced. The Peach genome v1 was used as a reference genome (Verde et al., 2013). VCFtool v0.1.11 was used to calculate depth and missingness from the unfiltered VCF file. Genotypes were filtered to leave only those with a quality of 98 or higher (high confidence SNP calls) with VCFtools. In addition, biallelic SNPs were converted to the PLINK format. The remaining individuals/sites were filtered according to missingness and allele frequency.

\section{Genetic Linkage Analysis}

A Z paternity test at $p=0.05$ using SNPs from each parent was applied in order to discern the parentage of the 272 seedlings. A total of 161 individuals were obtained from "Angeleno," 62 from "September King" and 15 from "September Queen," and the genotype "98-99" was the common female. One hundred fifty-three seedlings from the "98-99" $\times$ “Angeleno" progeny were used for genetic mapping. Genotyping errors, undercalling homozygotes and heterozygotes and SNPs with over $10 \%$ missing data were eliminated prior to genetic mapping. A total of 14,697 SNPs were obtained, including common SNPs (hkxhk; 21\%) and uncommon SNPs for "98-99" (lmxll; 26\%) and "Angeleno" (nnxnp; 53\%). Genetic linkage maps for each parent were constructed by JoinMap v.3.0 software (Van Ooijen, 2006) using the Kosambi mapping function with a frequency of recombination of 0.3 , and a LOD value over 10 was used for 
SNP clustering for each LG. Finally, 2 or 3 SNPs per one Mbp were selected for mapping in order to obtain a genetic distance between markers $<2 \mathrm{cM}$. Subsequently, only the first or second round of regression mapping was considered. Some SNPs with an unbalanced locus genotype frequency according to chi square distribution were eliminated, and each LG was recalculated. The coding of each SNP corresponds to a position in the Peach genome v.1.0 (Verde et al., 2013).

\section{Fruit Quality Trait Association and QTL Identification}

Marker-trait association analyses between SNPs and agronomic traits were performed using TASSEL v5. A General Lineal Model (GLM) using numeric data joined to genotype data and principal component analysis (PCA) was used for generating Manhattan plots for each trait and year. In addition, a Mixed Lineal Model (MLM) was applied using kinship data to define the relationship between individuals, because MLM sometimes has higher statistical power than GLM and may detect more true associations. The width of the QTL intervals was calculated by interval-mapping (a parametric test) and the Kruskal-Wallis test (a non-parametric test) using MAPQTL v4. LOD significance thresholds were determined for each trait and year with a test of 1,000 permutations between phenotypic and genotypic data using the "Permutation Test" function. The strongest marker cofactors of each QTL were identified by "Automatic Cofactor Selection" using SNP markers that exceeded the LOD significance threshold as the most significant marker. Linkage maps and QTL intervals were drawn using MapChart 2.3 software (Voorrips, 2002).

\section{RESULTS}

\section{Transmission and Correlations of Fruit Quality Traits in Japanese Plum}

For all the evaluated fruit quality traits we observed a great variability and noticeable segregation in the progenies (Figure 1). FW, IAD, FIRM, and SSC histograms revealed normal distribution according to Shapiro-Wilks test, indicating a polygenic nature and quantitative inheritance of these traits (Table S1), as previously reported in other Prunus species (Ruiz et al., 2010). RT histograms tended toward bimodal distribution especially for 2015 with mid-early and late-harvest seedlings, similar to findings in other Prunus species like peach (Eduardo et al., 2011; Pirona et al., 2013). SHP, SKC, FLSC, and OVC showed more categorical distributions (or Mendelian), due to the used phenotyping scale. FW ranged from 30 to $100 \mathrm{~g}$ in 2015 and between 20 and $70 \mathrm{~g}$ in 2016, while SSC_1 ranged from 10 to $23 \%$ for both years, and there were no apparent differences with SSC_2 values (Figure 1 and Table S1). For SHP most seedlings showed a spherical shape. Regarding fruit color, most frequent categories were red (3) and purple (4) skin color and yellow flesh, like their parents. Regarding OVC, most seedlings showed full color coverage (Figure 1). In the ANOVA for FW, $\mathrm{I}_{\mathrm{AD}}$, FIRM, and SSC, there were significant differences for the genotype and year factors, suggesting a significant environmental influence on these traits, as largely reported in Prunus (Eduardo et al., 2011). In the Kruskal-Wallis analysis, by the other hand, categorical traits such as RT, SKC, FLSC, and OVC did not show significant differences $(p>0.01)$ between years, suggesting that these traits might be mostly influenced by genotype, rather than the year effect (Tables 1, 2).

Regarding the correlations between years, the highest values were found for RT, FW, and $\operatorname{SKC~}(0.74,0.64$, and 0.80 , respectively), all of which were significant with $p<0.005$ (Table 3). Other phenotypic studies in peach (Quilot et al., 2004; Eduardo et al., 2011) and apricot (Ruiz et al., 2010; Salazar et al., 2013) show especially high inter-annual correlations for RT and SKC, but not so much for FW. These high correlations between years reveal that the genetic effect from genotypes is greater than the environmental effect for these traits, which makes them wellsuited to being improved. In addition, the genetic value of each genotype was calculated using BLUP coefficients for the main correlated traits between years. Negative coefficients were found for early ripening seedlings (mid-January), smaller size (30 g), green and red skin color and lower SSC (12\%), while positive coefficients were found for later ripening seedlings, bigger size (80 g), purple and black skin color and higher SSC (24\%), as expected (Figure $\mathbf{S 1}$ ).

\section{Genotype by Sequencing (GBS)}

Three FASTQ files (1 per plate) were generated, and over 220 million reads were read per lane, resulting in over 16 million tags for each plate or lane. This made it possible to get 2,272,102 good barcoded reads per each individual (Table S2). Similar results have been obtained in other Prunus species, with an average number of reads per genotype of 1,843,261 in cherry (Guajardo et al., 2015) and 2,333,869 in peach (Bielenberg et al., 2015). Finally, 5,230,374 tags were obtained after merging, and only three samples were failures (1.04\%). Of these tags, 2,244,856 (42.9\%) were aligned to unique positions, 190,411 (3.6\%) were aligned to multiple positions and 2,795,107 (53.4\%) could not be aligned in the peach genome v1 (Table S2). According to the HapMap files (SNP calls), 102,992 unfiltered SNPs and 42,909 filtered SNPs were counted, while in the VCF files, 744,927 SNPs were obtained (Table S3). In these VCF files, individual and site mean depth value reached 15 and 14, respectively, while both the individual and site missingness were around 0.14 (Table S4).

\section{Linkage Analysis and Identification of QTLs Linked to Fruit Quality Traits in Japanese Plum}

A total of 981 SNPs were mapped in the "98-99" × "Angeleno" progeny, with 479 SNPs for "98-99" and 502 SNPs for "Angeleno" covering a genomic region of 688.8 and $647.03 \mathrm{cM}$, respectively (Figure 3). This implies a mean genetic distance between markers of below $2 \mathrm{cM}$. As expected, the LG1 was the longest chromosome with $156.3 \mathrm{cM}$ in "98-99" and $153.1 \mathrm{cM}$ in "Angeleno." LG5 was the shortest chromosome, with 61.5 cM in "98-99" and 79.8 cM in "Angeleno." This supposes close to $45 \mathrm{Mbp}$ for LG1 and below $20 \mathrm{Mbp}$ for LG5 (Verde et al., 2013). The type of segregation was of 232 SNPs (23.7\%) for the 


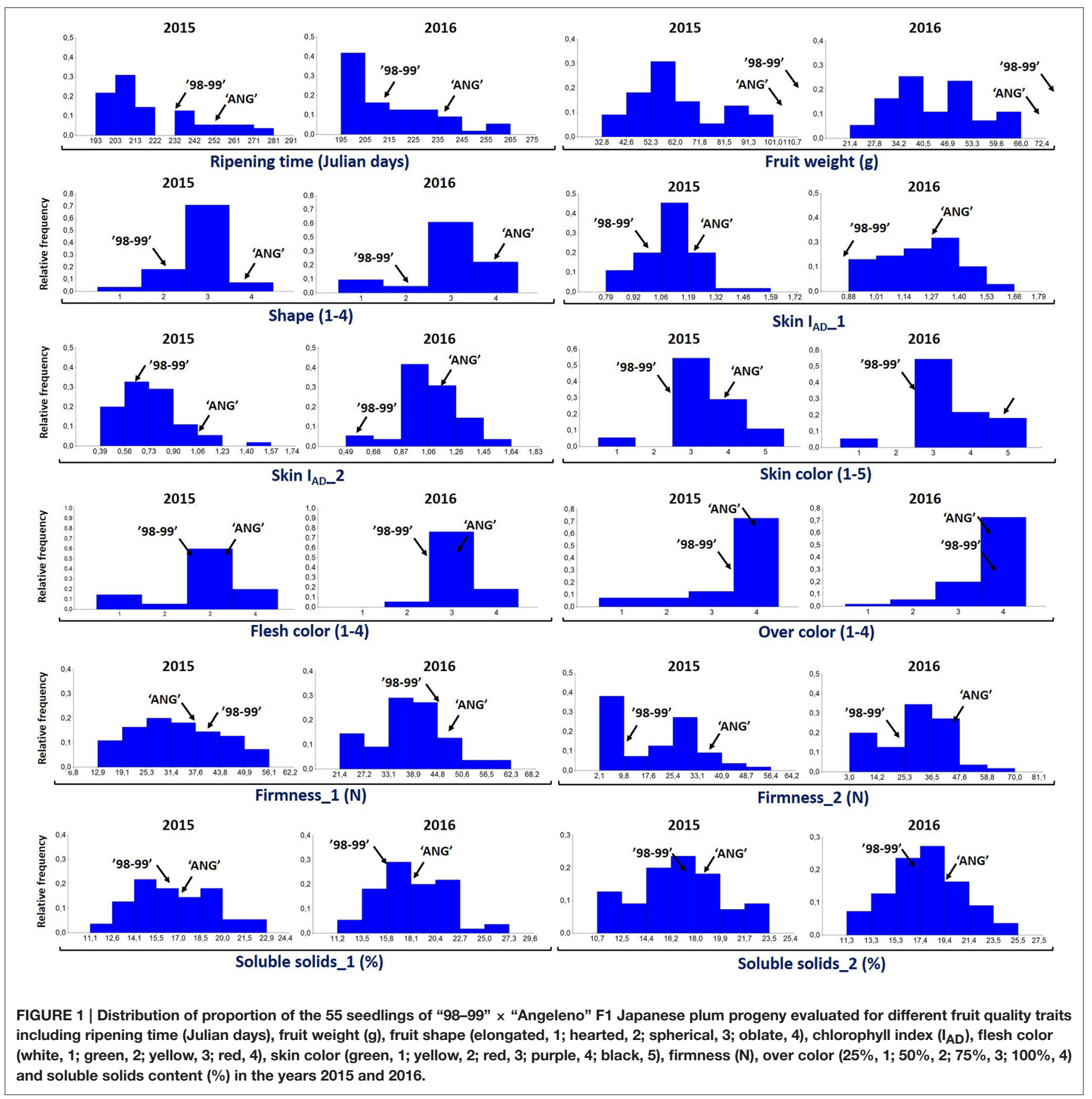

female parent $(<\operatorname{lmxll}>)$, 324 SNPs $(33 \%)$ for the male parent $(<\mathrm{nnxnp}>$ ) and 425 heterozygous SNPs (43.3\%) for both parents $(<\mathrm{hkxhk}>)$, agreeing with the higher heterozygosity observed in “Angeleno" respect to "98-99." These values were similar in some cherry progenies using GBS (Guajardo et al., 2015). GBS has also been used in F2 peach progenies (Bielenberg et al., 2015), and the map distance obtained was $666.1 \mathrm{cM}$, similar to that reached in this study. The genetic marker distance, however, was around $2.85 \mathrm{cM}$, which was bigger than that observed in the "98-99" $\times$ "Angeleno" genetic map (1.48 and $1.28 \mathrm{cM})$.
Manhattan plots were generated according to marker-trait association by GLM for the years 2015 and 2016, identifying hundreds of SNPs related with RT in LG4, with SKC in LG3 and LG4 and with FW and SHP mainly in LG7 (Figure 2). These results were confirmed by MLM, which detected the main QTLs for RT in LG4 at around 8 and $11 \mathrm{Mbps}$ and those for SKC in LG3 between 12 and 15 Mbps for both years. The FW QTL, on the other hand, was located in LG7 at around 16 to $20 \mathrm{Mbps}$ in 2016. All of these traits, especially RT and SKC, reached a phenotypic explanation variance (PEV) of around 30-40\% (Tables S7-S9). 
TABLE 1 | ANOVA analysis for the years 2015 and 2016 for different fruit quality traits of Japanese plum "98-99" x "Angeleno" progeny ( $n=55$ ), including ripening time, fruit weight, chlorophyll index ( $\left.\mathrm{I}_{\mathrm{AD}}\right)$, firmness, and soluble solids content.

\begin{tabular}{|c|c|c|c|c|c|c|}
\hline Factors & Traits & Sum of squares & Df & Mean square & $\boldsymbol{F}$ & Sig. \\
\hline \multirow[t]{7}{*}{ Genotype } & Fruit weight & 92326.36 & 54 & 1709.75 & 23.26 & $<0.0001$ \\
\hline & $\mathrm{I}_{\mathrm{AD} \_1}$ & 13.32 & 54 & 0.25 & 9.04 & $<0.0001$ \\
\hline & Firmness_1 & 34463.77 & 54 & 638.22 & 10.71 & $<0.0001$ \\
\hline & Soluble solids_1 & 4614.72 & 54 & 85.46 & 17.43 & $<0.0001$ \\
\hline & IAD_2 & 20.30 & 54 & 0.38 & 13.18 & $<0.0001$ \\
\hline & Firmness_2 & 85634.74 & 54 & 1585.83 & 17.48 & $<0.0001$ \\
\hline & Soluble solids_2 & 4446.48 & 54 & 82.34 & 17.94 & $<0.0001$ \\
\hline \multirow[t]{7}{*}{ Year } & Fruit weight & 46942.76 & 1 & 46942.76 & 638.58 & $<0.0001$ \\
\hline & $\mathrm{I}_{\mathrm{AD} \_1}$ & 1.04 & 1 & 1.04 & 37.95 & $<0.0001$ \\
\hline & Firmness_1 & 2064.63 & 1 & 2064.63 & 34.66 & $<0.0001$ \\
\hline & Soluble solids_1 & 238.75 & 1 & 238.75 & 48.70 & $<0.0001$ \\
\hline & $\mathrm{I}_{\mathrm{AD} \_2}$ & 12.25 & 1 & 12.25 & 429.72 & $<0.0001$ \\
\hline & Firmness_2 & 12871.32 & 1 & 12871.32 & 141.89 & $<0.0001$ \\
\hline & Soluble solids_2 & 98.08 & 1 & 98.08 & 21.37 & $<0.0001$ \\
\hline
\end{tabular}

Fruit weight was evaluated at the harvest date, while $I_{A D}$, firmness and soluble solids were evaluated at two maturity states, at the harvest date (_1) and 1 week after harvest (_2).

TABLE 2 | Kruskal-Wallis analysis for the years 2015 and 2016 for different agronomic traits of Japanese plum "98-99" x "Angeleno" progeny ( $\mathrm{n}$ = 55), including ripening time, fruit shape, skin color, flesh color, and over color evaluated at the harvest date.

\begin{tabular}{|c|c|c|c|c|c|c|}
\hline Factor & Trait & Average & $S D$ & Median & $\mathbf{H}$ & $p$ \\
\hline \multirow[t]{5}{*}{ Genotype } & Ripening time & 218.44 & 8.38 & 212 & 95.43 & 0.0004 \\
\hline & Shape & 2.93 & 0.23 & 3 & 392.92 & $<0.0001$ \\
\hline & Skin color & 3.43 & 0.16 & 3 & 472.45 & $<0.0001$ \\
\hline & Flesh color & 3.11 & 0.14 & 3 & 282.36 & $<0.0001$ \\
\hline & Over color & 3.45 & 0.41 & 4 & 282.21 & $<0.0001$ \\
\hline \multirow[t]{5}{*}{ Year } & Ripening time & 218.44 & 20.41 & 212 & 0.28 & 0.5923 \\
\hline & Shape & 2.915 & 0.73 & 3 & 10.59 & 0.0002 \\
\hline & Skin color & 3.405 & 0.91 & 3 & 0.12 & 0.6976 \\
\hline & Flesh color & 3.095 & 0.55 & 3 & 0.05 & 0.7632 \\
\hline & Over color & 3.44 & 0.90 & 4 & 0.21 & 0.5919 \\
\hline
\end{tabular}

TABLE 3 | Pearson correlation coefficients for different agronomic traits for the years 2015 (below diagonal) and 2016 (above diagonal) in 55 "98-99" $\times$ "Angeleno" plum seedlings.

\begin{tabular}{|c|c|c|c|c|c|c|c|c|c|c|c|c|}
\hline & RT & FW & SHP & $I_{A D \_1}$ & SKC & FLSC & ovc & FIRM_1 & SSC_1 & $\mathrm{I}_{\mathrm{AD} \_2}$ & FIRM_2 & SSC_2 \\
\hline $\mathrm{RT}$ & $0.74^{\star \star \star}$ & $0.44^{\star \star \star}$ & -0.21 & -0.01 & $-0.52^{\star \star \star}$ & $-0.27^{\star}$ & $-0.75^{\star \star \star}$ & 0.58 & -0.13 & 0.13 & $0.60^{\star \star \star}$ & $-0.36^{\star \star}$ \\
\hline FW & $0.35^{\star \star}$ & $0.64^{\star \star \star}$ & $-0.46^{\star \star \star}$ & -0.03 & -0.23 & -0.03 & $-0.32^{\star}$ & 0.08 & $-0.46^{\star \star \star}$ & -0.14 & 0.12 & $-0.45^{\text {***}}$ \\
\hline SHP & -0.06 & -0.05 & $0.38^{\star \star \star}$ & -0.06 & 0.25 & -0.04 & 0.10 & 0.21 & $0.32^{*}$ & -0.02 & 0.17 & $0.33^{\star *}$ \\
\hline$I_{A D \_1}$ & $0.39^{\star \star \star}$ & -0.02 & 0.11 & 0.20 & 0.13 & -0.02 & -0.06 & -0.07 & 0.13 & $0.67^{\star \star \star}$ & -0.09 & 0.07 \\
\hline SKC & -0.21 & $0.27^{\star}$ & 0.03 & -0.17 & $0.80^{\star \star \star}$ & 0.11 & $0.57^{\star \star \star}$ & $-0.28^{*}$ & $0.42^{\star \star \star}$ & 0.06 & $-0.28^{\star}$ & $0.51^{\text {***}}$ \\
\hline FLSC & -0.21 & 0.06 & 0.19 & -0.14 & $0.31^{\star}$ & 0.22 & 0.25 & -0.22 & -0.03 & 0.04 & -0.23 & 0.04 \\
\hline OVC & 0.01 & 0.20 & -0.09 & -0.18 & $0.37^{\star \star \star}$ & 0.06 & $0.37^{\star \star}$ & $-0.40^{\star \star \star}$ & 0.02 & -0.10 & $-0.36^{\star \star}$ & 0.18 \\
\hline FIRM_1 & -0.03 & $-0.36^{\star \star}$ & 0.18 & -0.01 & $-0.44^{\star \star \star}$ & -0.19 & -0.26 & $0.33^{\star}$ & -0.01 & 0.14 & $0.84^{\star \star \star}$ & -0.18 \\
\hline SSC1 & $0.33^{\star \star}$ & 0.08 & 0.04 & $0.17^{\star}$ & $0.33^{*}$ & 0.14 & 0.05 & -0.13 & 0.35 & 0.16 & -0.08 & $0.93^{\star \star \star}$ \\
\hline IAD_2 & $0.38^{* *}$ & 0.14 & 0.02 & 0.32 & 0.17 & 0.10 & $0.34^{\star \star}$ & -0.19 & 0.17 & $0.59^{\star \star \star}$ & $0.31^{\star}$ & 0.03 \\
\hline FIRM_2 & 0.21 & $-0.27^{\star}$ & 0.00 & -0.04 & $-0.54^{\star \star \star}$ & -0.11 & -0.13 & $0.53^{\star \star \star}$ & -0.07 & 0.16 & $0.30^{*}$ & -0.24 \\
\hline SSC_2 & $0.37^{\star \star}$ & 0.08 & -0.12 & 0.22 & $0.28^{\star}$ & 0.11 & 0.07 & -0.12 & $0.75^{\star \star \star}$ & 0.22 & 0.01 & $0.35^{\star \star}$ \\
\hline
\end{tabular}

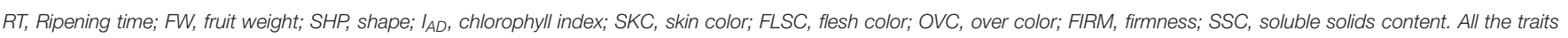
were evaluated at the harvest date, while $I_{A D}$, firmness and soluble solids were evaluated at two maturity states, at the harvest date (_1) and 1 week after harvest (_2). $P$ < 0.05 , ${ }^{\star \star} P<0.01,{ }^{\star \star \star} P<0.005$. 

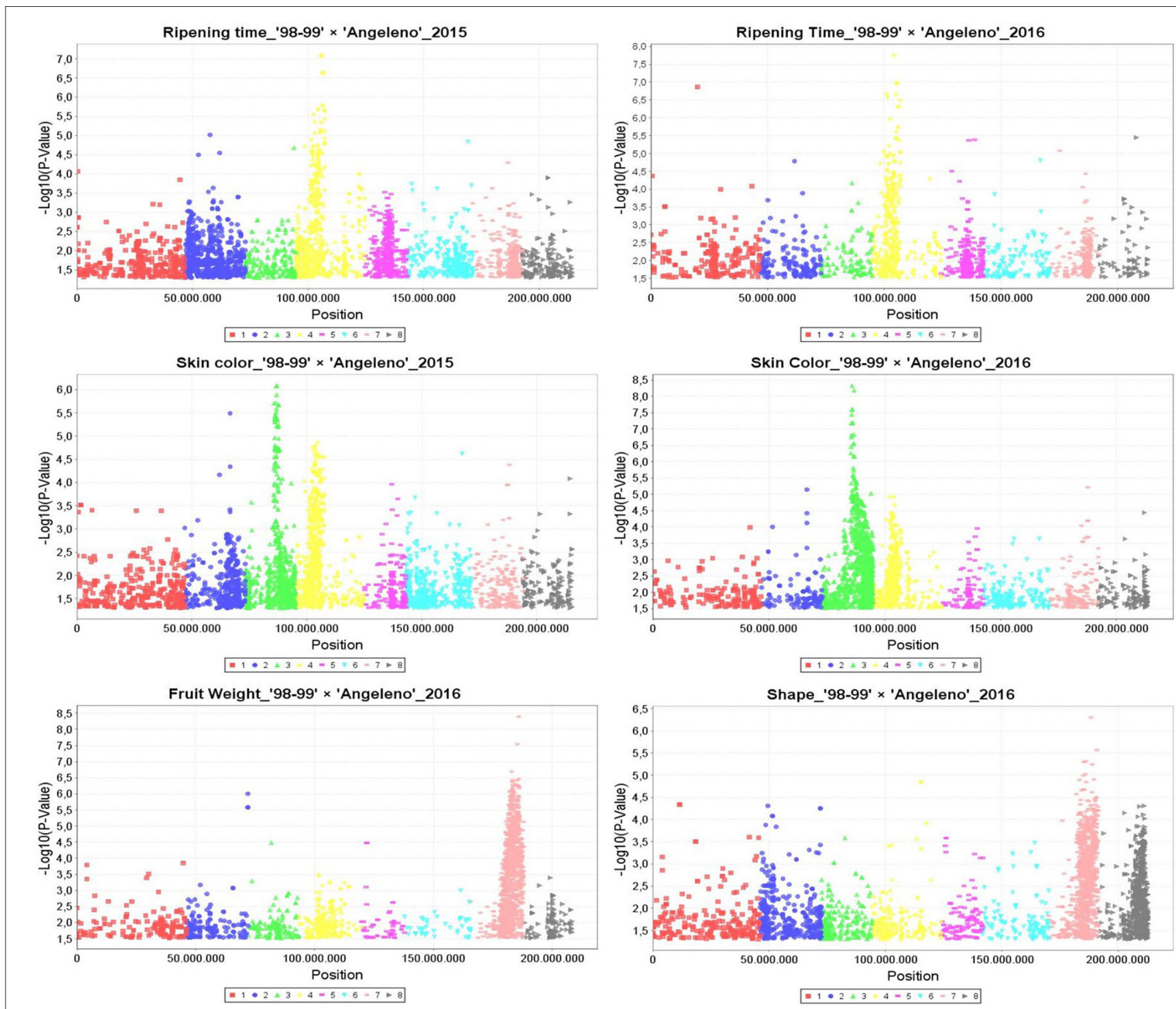

FIGURE 2 | Manhattan plots calculated by General Linear Model (GLM) in TASSEL5 for the main QTLs identified linked to ripening time, skin color, fruit weight, and fruit shape in the years $\mathbf{2 0 1 5}$ and 2016. Vertical axis are indicating the - $\log _{10}(p$-value) and horizontal axis are indicating the position in millions pair of bases of each SNP aligned to Peach genome v1.

As for the QTL mapping analysis, several QTLs (including those previously mentioned) were identified by IM and KW for 2015 and 2016. The majority of these QTLs were localized in LG3, including $\mathrm{I}_{\mathrm{AD}_{-}} 1-2, \mathrm{SKC}$, and OVC, and in LG4, including RT, SKC, OVC, and FIRM. SSC QTLs were identified in LG1 and LG6 (Table 4 and Figure 3). The most important QTLs identified were for RT, SKC and FW. According to IM, the RT QTL was strongly localized in LG4 between 6 and $12 \mathrm{Mbp}$ with a LOD value over $5(\operatorname{LOD} \alpha 0.01$; Figure 3$)$. This long QTL interval is due to the fact that there are many SNPs co-localizing in LG4, indicating that this chromosome has a strong influence on this trait, as mentioned above (Figure 2). In addition, this QTL reached a maximum LOD value of 8.45 and a PEV value of over $40 \%$ for both years (Table 4 and
Tables S5, S6). S4_11357872 and S4_12564956 were selected as cofactors for "98-99" in 2015 and 2016, while a set of five cofactors from S4_9765977 to S4_11967712 were selected for "Angeleno" in 2016, with S4_11967712 reaching a PEV value of $84.9 \%$ (Table S6). The heterozygous genotypes (np in SNP S4_11967712) from "Angeleno" present on average earlier ripening time and the homozygous (nn) with later ripening time, with an average difference of close to 30 days in 2015 and 20 days in 2016 .

Regarding the SKC QTL, LG3, and LG4 were the LGs most linked to this trait for both parents and years (Tables 4 and Tables S5, S6). The SKC QTL co-localized in LG4 in the same genomic region as RT for both years and in the same genomic region as the OVC QTL in 2016. This may be due to the 
TABLE 4 | QTL analysis by interval mapping (parametric test) and mapping information for fruit quality traits in a F1 Japanese plum progeny of "98-99" x "Angeleno."

\begin{tabular}{|c|c|c|c|c|c|c|c|c|c|}
\hline Trait & Year & Parent & QTL & LG & IM_95\% (cM) & Location & Nearest marker & LOD & PEV \\
\hline \multirow[t]{4}{*}{ Ripening time } & 2015 & 98-99 & $\mathrm{RT}$ & 4 & [25.0; 52.4] & 43.2 & S4_11357872 & 6.73 & 46.3 \\
\hline & 2015 & ANG & $\mathrm{RT}$ & 4 & {$[17.7 ; 41.6]$} & 36.1 & S4_11357872 & 7.53 & 51.6 \\
\hline & 2016 & 98-99 & $\mathrm{RT}$ & 4 & [25.0; 52.0] & 43.2 & S4_11357872 & 6.51 & 63.2 \\
\hline & 2016 & ANG & $\mathrm{RT}$ & 4 & [17.0; 41.6] & 36.1 & S4_11357872 & 8.45 & 63.5 \\
\hline \multirow[t]{2}{*}{ Chlorophyll index } & 2015 & 98-99 & $\mathrm{I}_{\mathrm{AD} \_} 1-2$ & 3 & {$[19.2 ; 40.1]$} & 35.7 & S3_6856158 & 4.82 & 34.8 \\
\hline & 2015 & ANG & $\mathrm{I}_{\mathrm{AD} \_1-2}$ & 3 & {$[17.2 ; 34]$} & 32.1 & S3_8549572 & 5.14 & 39.4 \\
\hline \multirow[t]{8}{*}{ Skin color } & 2015 & $98-99$ & SKC & 3 & {$[43.2 ; 57.2]$} & 49.7 & S3_14698248 & 6.61 & 43.3 \\
\hline & 2015 & 98-99 & SKC & 4 & [25.0; 52.0] & 42.1 & S4_10872195 & 6.54 & 44.8 \\
\hline & 2015 & ANG & SKC & 3 & [48.3; 67.0] & 53.8 & S3_13359114 & 7.07 & 44.7 \\
\hline & 2015 & ANG & SKC & 4 & {$[17.7 ; 41.6]$} & 31.1 & S4_9700717 & 5.16 & 35.9 \\
\hline & 2016 & 98-99 & SKC & 3 & {$[40.1 ; 75.4]$} & 45.6 & S3_13221856 & 5.12 & 34.9 \\
\hline & 2016 & 98-99 & SKC & 4 & [27.1; 52.0] & 42.1 & S4_10872195 & 5.56 & 41.3 \\
\hline & 2016 & ANG & SKC & 3 & [39.0; 79.8] & 52.3 & S3_12879559 & 8.15 & 50.4 \\
\hline & 2016 & ANG & SKC & 4 & [21.0; 46.0] & 38.8 & S4_11967712 & 6.04 & 40.1 \\
\hline \multirow[t]{4}{*}{ Over color } & 2015 & 98-99 & OVC & 4 & {$[41.9 ; 42.1]$} & 41.9 & S4_10696055 & 5.1 & 33.3 \\
\hline & 2015 & ANG & OVC & 3 & [63.1; 63.8] & 63.8 & S3_14754388 & 3.68 & 67.6 \\
\hline & 2016 & 98-99 & OVC & 4 & [25.9; 59.6] & 39.6 & S4_10173649 & 9.21 & 55.6 \\
\hline & 2016 & ANG & OVC & 4 & [17.7; 41.6] & 38.8 & S4_11967712 & 8.01 & 48.9 \\
\hline \multirow[t]{4}{*}{ Soluble solids } & 2015 & 98-99 & SSC_2 & 1 & {$[56.1 ; 74.3]$} & 63.6 & S1_19630503 & 3.70 & 27.1 \\
\hline & 2015 & $98-99$ & SSC_1 & 6 & [46.3; 47.5] & 47.5 & S6_22808265 & 3.61 & 31.3 \\
\hline & 2015 & ANG & SSC_2 & 1 & [57.8; 58.5] & 58.5 & S1_16669374 & 3.71 & 27.8 \\
\hline & 2015 & ANG & SSC_1 & 6 & [55.5; 57.0] & 57.0 & S6_23276829 & 4.25 & 28.7 \\
\hline \multirow[t]{2}{*}{ Fruit weight } & 2016 & $98-99$ & FW & 7 & [74.0; 93.7] & 74.2 & S7_18296863 & 5.76 & 47.9 \\
\hline & 2016 & ANG & FW & 7 & {$[44.0 ; 65.4]$} & 58.4 & S7_20598519 & 5.79 & 39.0 \\
\hline \multirow[t]{2}{*}{ Shape } & 2016 & 98-99 & SHP & 7 & [74.0; 93.7] & 74.2 & S7_18296863 & 4.75 & 42.5 \\
\hline & 2016 & ANG & SHP & 7 & [35.2; 65.4] & 61.9 & S7_20956328 & 4.73 & 36.1 \\
\hline
\end{tabular}

$L G$, linkage group; $L O D$, logarithm of odds; $I M$, interval mapping at $L O D$ threshold $\leq 0.05$.

pleiotropic effect of certain genes that are simultaneously related to maturity date and fruit skin color, as has been described by other authors like Eduardo et al. (2011). For both QTLs, the heterozygous allele from "Angeleno" tended toward purple SKC (4) and $100 \%$ OVC (4). The occurrence of the OVC QTL only in 2016 may be explained by an environmental effect. The increased insolation in that year caused the fruits to obtain a much fuller color, which we could also consider as a genetic effect, because the conditions in 2016 probably made it possible for the expression of this trait to be more intense. However, the most important QTL for SKC was strongly localized in LG3 between 52 and 61 cM, especially in "Angeleno" (Figure 3). Cofactors between 12 and $14 \mathrm{Mbp}$ were selected in "Angeleno" for both years, and the most significant was S3_12879559 in 2016, which reached over $80 \% \mathrm{PEV}$. This means that the seedlings showing heterozygous genotypes on SNPs segregating for "Angeleno" have a darker color than homozygous genotypes, whose fruits tended to have a red skin color (phenotypic mean of 4.11 in np seedlings vs. a mean of 2.85 in nn seedlings; Table S6). In addition, alleles from
“98-99" in this LG3 QTL, although with less clear allele effects among years, show also to contribute significantly to the trait variability in this progeny.

In addition, a QTL was identified in LG3 related to the chlorophyll index calculated as the difference between $\mathrm{I}_{\mathrm{AD}}$ at different maturity states (I $\mathrm{AD}_{1}$ 1-2). For this QTL, S3_4166803 and S3_8549572 were identified as the cofactors of "98-99" and "Angeleno," respectively. The explained phenotypic variance was over 30\% for both parents (Tables 4 and Tables S5, S6). These QTLs values are undoubtedly due to the significant difference between both parents in terms of chlorophyll degradation. The cultivar "98-99" undergoes greater chlorophyll degradation than "Angeleno," a suppressed climacteric cultivar (Singh et al., 2012), which could be related to the higher softening rate of "98-99."

Moreover, QTLs for FW and SHP were also identified in 2016, which co-localized in the same position in the LG7 of "Angeleno," between 16 and $20 \mathrm{Mbp}$ (Figure 3 and Table 4). These QTLs may be related to the correlation between FW and SHP in the same year (Table 3), which indicates that lower fruit weight is related to 


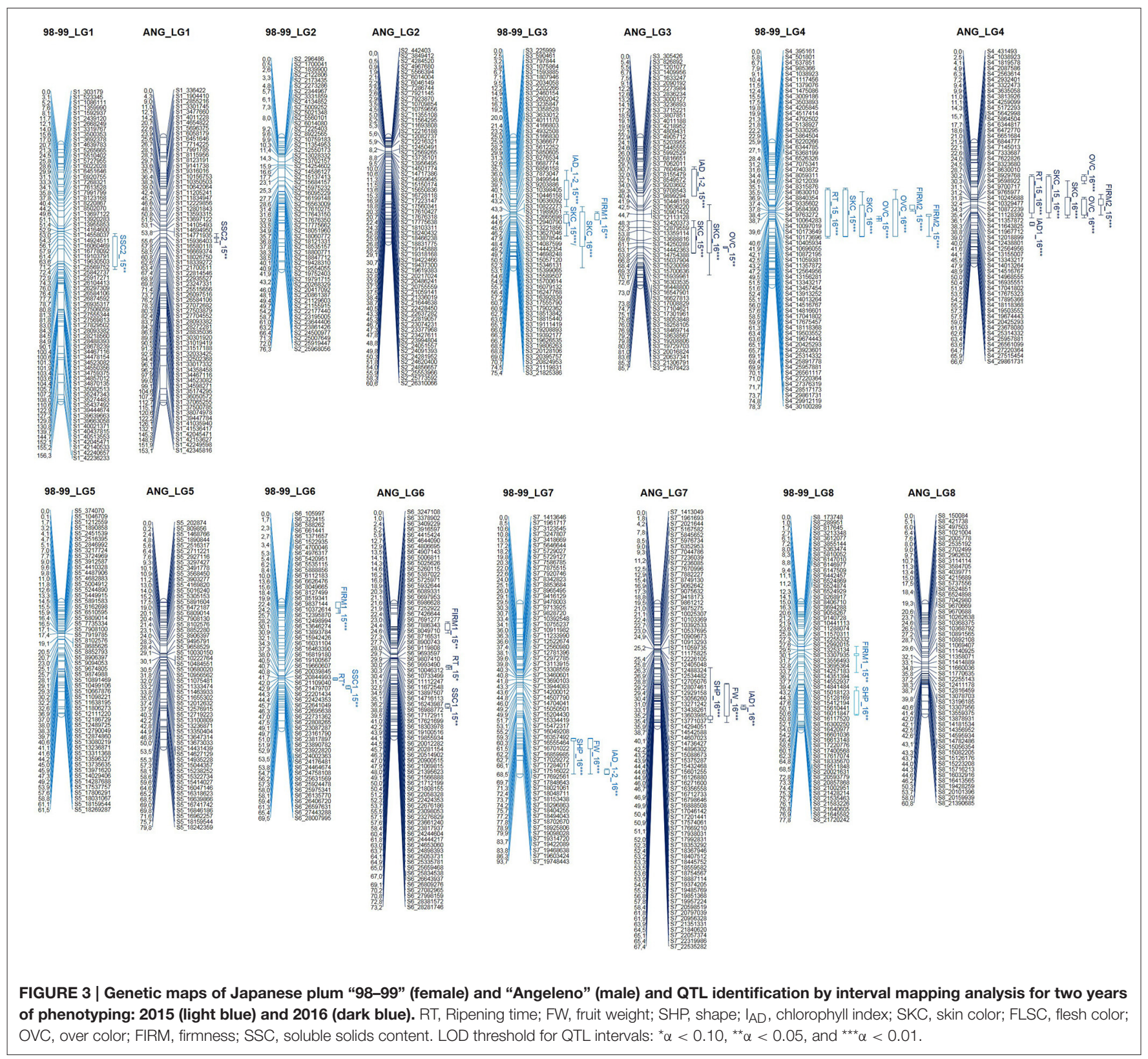

more elongated fruits. Nevertheless, we must emphasize that this correlation is not very high because there is no clear segregation between spherical (3) and elongated fruits (1). Both QTLs are thus related to fruit size, and in both cases the PEV value is close to $40 \%$. This means an average fruit weight of above $50 \mathrm{~g}$ or below $40 \mathrm{~g}$ depending on the allelic class, with S7_20598519 being the most important cofactor (Tables S5, S6). Contrary to ripening time, QTLs for fruit size and weight do not appear to be strongly linked to a particular linkage group.

Finally, as for SSC, two QTLs were identified in LG1 and LG6 for 2015 (Figure 3 and Table 4). The SSC QTL at maturity completion (SSC_2) for "98-99" was localized at around 54-76 cM, and S1_19630503 was selected as a cofactor, reaching a PEV value of around $25 \%$ of difference between phenotypic classes
(15.5-18.5\%, Table S5). To the contrary, the second QTL for SSC at harvest (SSC_1) for "Angeleno" was identified in LG6 at around 55-57 cM and S6_23276829 was selected as a cofactor, reaching a PEV value of close to $30 \%$. In this case, S6_23276829 determines three phenotypic classes from ranging 14.5 to 18.4 (Table S6).

\section{DISCUSSION}

Assisted selection using molecular markers is not an easy path for improving the quantitative traits in any plant species, so it is often preferred to study qualitative traits, which have more easily predictable behavior and are generally associated with few genes. 
Improving fruit quality, however, is one of the priority aims for any breeding program, which is a great challenge because the majority of quality traits are quantitatively inherited. Ripening time, fruit size, soluble solids content, acidity and antioxidant and functional-food compounds related to fruit color are perhaps the most desirable traits for improving fruits from the point of view of phenology, organoleptic quality and health. However, postharvest fruit behavior is also highly important, and increasing our knowledge of all the factors involved in the fruit ripening process may provide us with molecular tools for selecting seedlings with less perishable fruits and therefore a longer useful life.

The use of NGS-based molecular tools such as GBS demonstrate the great importance of genomes sequencing, which has been successfully implemented in our F1 plum population, generating very saturated parental genetic maps with a mean distance between markers $<2 \mathrm{cM}$. Therefore, GBS is profiled as an appropriate application tool for breeding programs of this species, allowing a greater genetic depth and more accurate QTL detection. Moreover, the results obtained in the "98-99" $\times$ "Angeleno" progeny showed similar behavior to other Prunus species and provide promising information about QTLs from a phenological point of view, especially regarding ripening time and fruit quality traits like fruit weight, fruit skin color and soluble solids content. Among these mentioned traits, in our study we determined the occurrence of QTL of strong and consistent effect through harvest seasons for ripening time, skin color, and chlorophyll degradation.

Ripening time QTL is undoubtedly important as it can help us select early and late seedlings according to our needs. In the studied F1 progeny, MD showed a bimodal distribution, indicating that segregation of few loci of major effect and an undetermined number of loci of minor effect for this trait. In most of reported segregations of this trait in other F1 progenies of Prunus species, a continuous segregation was observed (e.g., "BxO" in Eduardo et al., 2011, and "CxEL" in Pacheco et al., 2014), supposedly depending in the genetic backgrounds of the parents. Most seedlings (around a 50\%) show mid-early ripening dates of 215 or less Julian days, suggesting a dominance effect from alleles of "98-99" parent. Moreover, the occurrence of this QTL is highly conserved within Prunus species, being related the MD locus with NAC family transcription factors (Pirona et al., 2013) which are involved in abiotic stress tolerance (Shen et al., 2017). In our population cofactors between S4_9765977 to S4_11967712 were identified in the same genomic region of MD locus. The location of this QTL has been previously reported in the most important commercial Prunus species such as peach, apricot, and cherry (Eduardo et al., 2011; Dirlewanger et al., 2012; Pirona et al., 2013; Salazar et al., 2013, 2016; Nuñez-Lillo et al., 2015). We can therefore assert that this QTL occurs in a genomic region that is highly conserved in different Prunus species. Further studies on this genomic region in F2 peach populations have allowed the location a $M D$ locus of $220 \mathrm{~kb}$ (ppa008301m) as a candidate gene encoding transcription factors of the NAC family (Pirona et al., 2013). Another more recent study in peach and nectarine localized the same QTL in LG4 at around 31 to $42 \mathrm{cM}$ and identified five candidate genes related to maturation date and nine candidate genes for flesh mealiness, suggesting ANAC072 and ppa010982m (ERF4) as transcription factors (TFs) involved in the expression of both traits (Nuñez-Lillo et al., 2015). NuñezLillo et al. (2015) and Eduardo et al. (2015) suggest that mealiness and slow ripening could be related with maturation date, which leads us to study these traits together in following phenotyping seasons, in order to decipher the biological processes underlying this strong pleiotropic effect. Eduardo et al. (2015) reported that the slow ripening trait is determined for a single gene $(\mathrm{Sr} / \mathrm{sr}$ ) and that this gene is mapped in the same region of the $\mathrm{MD}$ locus in peach. The MD locus is therefore partly responsible for maturity date variability and could be related with the sr allele, which could confer desirable postharvest traits such as slow ripening.

Regarding SKC trait in the studied cross, most seedlings had fruits with red or violet colors, suggesting a dominant effect of alleles from darker parent ("Angeleno"). This strong effect was confirmed by the finding QTLs segregating in both parents, on two harvest seasons and located in a region that spans between positions 10,446,158 and 14,698,248 of chromosome 3 . Marker showing the most significant effect in trait variation was S3_13359114, segregating only in "Angeleno" (Expl\% $=41.9$ 85.5). Other important component of this trait corresponded to the QTLs mostly detected in "98-99" parent, and co-localizing with ripening time QTLs. Several QTLs for fruit skin color have been reported for peach in different LGs: in LG2 (Quarta et al., 2000); in LG2 and LG6 (Verde et al., 2002); in LG5 (Quilot et al., 2004); and in LGs 3, 4, 6, and 7 (Eduardo et al., 2011). Moreover, Dirlewanger et al. (2004b) and Martínez-García et al. (2013b) identified QTLs for red and yellow flesh color in LG1. However, as occurred for RT in LG4, the SKC QTL in LG3 seems to have a greater effect given that other authors have identified major QTLs in this LG in different Prunus species, indicating that the occurrence of this QTL may be highly conserved within Prunus species (Sooriyapathirana et al., 2010; Socquet-Juglard et al., 2013; Frett et al., 2014). In cherry, for example, Sooriyapathirana et al. (2010) localized a major QTL for skin and flesh color in LG3 at around $54 \mathrm{cM}$ with a PEV value of around $80 \%$. This QTL co-localized in the same interval in the "98-99" $\times$ "Angeleno" progeny. In addition, PavMYB10, a homologous gene to apple and Arabidopsis, was identified as a candidate gene (Allan et al., 2008). In apricot, Socquet-Juglard et al. (2013) also identified an important QTL for ground color in LG3, and the nearest marker was located at around $55 \mathrm{cM}$. Frett et al. (2014) also localized a similar QTL for blush in LG3, identifying candidate genes involved in the flesh coloration of peach (PprMYB10), cherry (PavMYB10) and apple $(M d M Y B 1 / M d M Y B A / M d M Y B 10)$. In apple, several authors claim that anthocyanin biosynthesis is regulated by MYB transcription factors that are positively correlated with red skin color (Takos et al., 2006; Ban et al., 2007; Chagné et al., 2007; Allan et al., 2008). Moreover, the SNP S3_12879559 is colocalizing close to a MYB transcription factor in our population (Table S10). This suggests similar genetic control of fruit skin color within rosaceous species. In P. salicina (González et al., 2016) several EST-SSRs have recently been developed from genes coding for proteins involved in the flavonoid pathway, in order to explore the genetic structure of 29 accessions. 
According to peach genome v1 (Verde et al., 2013), most of these SSRs are located between positions 12,842,509 and $12,842,693$ of chromosome 3 , close to the nearest marker for the SKC QTL from the "98-99" × "Angeleno" population, suggesting that the same genes could be involved in fruit skin color and the flavonoid pathway, and confirming that flavonoid pathway comprises molecular processes that are of key importance in the genetic control of skin color trait in rosaceous species. Importantly, the chlorophyll degradation QTL identified upstream to skin color QTL of LG3 offers to the community a new approach for the identification of seedlings potentially with a good postharvest behavior because a faster chlorophyll degradation is often related to more abrupt fruit senescence and fruit softening. As reported by Wu et al. (2011), chlorophyll degradation is related to decrease in polygalacturonase and pectin methylesterase, given that chlorophyll variation is an indicator of fruit ripening and senescence. Further studies are required for fine mapping of this region and identification of genes involved in this physiological process of great commercial importance.

FW QTL located in the LG7 means a promising QTL because usually fruit weight or fruit size are strongly influenced by climatic conditions, with a very polygenic nature, as reported in Prunus species for different LGs. In fact, contrary to ripening time, QTLs for fruit size and weight do not appear to be strongly linked to a particular linkage group. For example, in peach, Quilot et al. (2004) placed different fruit diameter QTLs in LGs $1,4,5,6$, and 7 and fruit weight QTLs in LGs 1, 2, 4, 5, and 7, while Cantín et al. (2010) located the fruit diameter QTLs in LG4. Also in peach, Eduardo et al. (2011) located a fruit weight QTL in LG6, while in cherry, Zhang et al. (2010) identified fruit size QTLs in LG2 and LG6. More recently, Campoy et al. (2015) located major QTLs linked to sweet cherry fruit size control in LG5 and identified different candidate genes along the QTL interval. Earlier, De Franceschi et al. (2013) identified 23 genes from Cell Number Regulator (CNR) progeny related to FW in cherry in LG2 and LG6, and they found PavCNR12 and PavCNR20 in the QTL intervals. Genes from CNR progeny may thus control fruit size by increasing the cell number and organ size in Prunus species as well as in tomato and maize (Frary et al., 2000; Guo et al., 2010). In a F2 peach population, Da Silva Linge et al. (2015) recently identified several QTLs related to FW in different LGs. The most important QTL was localized in LG7, and it showed a LOD value over 10 and a PEV value of around 20\%. The nearest FW QTL marker was located at around $40 \mathrm{cM}$, similar to findings in the "98-99" $\times$ "Angeleno" progeny. To the contrary, in an F1 nectarine population, Zeballos et al. (2016) located the most important QTLs for FW in LG4, with a maximum PEV value of around 50\%. In cherry, Rosyara et al. (2013) identified six QTLs for fruit size in LG1, LG3, and LG6 with the Bayesian approach, using different progenies and their ancestors simultaneously. Taking a similar approach in peach, Fresnedo-Ramírez et al. (2016) were also able to identify several QTLs for fruit diameter and fruit weight along the genome, supporting the fact that, although its complexity, actually available genomic, genetic and statistical tools allow the genetic dissection of this trait.
Finally, several authors have described QTLs related to SSC and sugar metabolism (fructose, glucose, and sucrose) along the Prunus genome, especially in intraspecific and inter-specific peach crosses (Dirlewanger et al., 1999; Quarta et al., 2000; Etienne et al., 2002; Verde et al., 2002; Quilot et al., 2004; Eduardo et al., 2011; Illa et al., 2011). This indicates the polygenic character of this trait linked to different chromosomes. Recently, Desnoues et al. (2016) studied QTLs related to sugar metabolism during fruit development in peach. These authors identified five QTLs for sucrose and located the most important QTL in LG1, with a percentage of trait variability explained of between 40 and $80 \%$. These authors also identified the following four candidate genes: SUGAR TRANSPORTER (Prupe.1G133300); INVERTASE INHIBITOR (Prupe.1G131900, Prupe.1G132000, Prupe.1G132300); and SUSY (Prupe.1G131700).

\section{CONCLUSION}

In this work we reported genomic regions strongly correlated with important fruit quality traits such as ripening time (RT), chlorophyll degradation index ( $\mathrm{I}_{\mathrm{AD}}$ 1-2), skin color (SKC), over color (OVC), soluble solids content (SSC), weight (FW), and shape (SHP). QTLs with a significant and consistent effect through years were found for RT, $\mathrm{I}_{\mathrm{AD}}{ }_{1-2}$, and SKC. Due to the complexity of these polygenic traits, it will be necessary to carry out a more detailed study in order to validate the reported QTLs, considering the phenotyping of more seedlings, in order to include more recombinants, and thus obtain QTLs covering narrower genomic regions for fine mapping of the traits; moreover, more phenotyping years must be included to have a more precise estimation of genetic and seasonal effects on these traits. Moreover, new molecular markers specifically designed for each QTL region must be included in order to assist fine mapping of genes controlling these traits. Such further studies would make it possible to use MAS as a breeding tool for Japanese plum. Finally, from a postharvest point of view, non-destructive control of the firmness of the fruit during the critical maturation period (Infante et al., 2011b) would be necessary for investigating a possible relationship between the softening rate and a locus of the genome.

\section{AUTHOR CONTRIBUTIONS}

JS: Writer and analyst of results. IP: Analyst of results and reviewer. PS: Management and technical support. PZ and CS: Laboratory technician. MA and DV: Adviser and rewiewer. DR and PM: Writer and reviewer. RI: Corresponding author and reviewer.

\section{ACKNOWLEDGMENTS}

This research has been sponsored by University of Chile and it's been supported by National Commission for Scientific and Technological Research (CONICYT) of Chile government through FONDECYT Postdoctoral fellowship No. 3160080, 
FONDECYT Start into Research No. 11150662 and Program of Insertion Into Academy No. 79140020.

\section{SUPPLEMENTARY MATERIAL}

The Supplementary Material for this article can be found online at: http://journal.frontiersin.org/article/10.3389/fpls.2017. 00476/full\#supplementary-material

Figure S1 | Best Linear Unbiased Predictors (BLUPs) coefficients of each seedling for ripening time, fruit weight, skin color, and soluble solids content.

Table S1 | Summary of descriptive statistics and normality test of Shapiro-Wilks of the evaluated traits.

Table S2 | Summary of FastQ files and alignment results obtained by GBS.
Table S3 | Summary of SNPs obtained from calling SNPs.

Table S4 | Depth and missingness from the unfiltered VCF file.

Table S5 | Summary of the most important SNPs as cofactors related to different QTLs in the "98-99" parent for 2015 and 2016.

Table S6 | Summary of the most important SNPs as cofactors related to different QTLs in the "Angeleno" parent for 2015 and 2016.

Table S7 | Marker trait association by Mixed Linear Model (MLM) by TASSEL v5 in 2015.

Table S8 | Marker trait association by Mixed Linear Model (MLM) by TASSEL v5 in 2016.

Table S9 | Marker trait association by Mixed Linear Model (MLM) by TASSEL v5 for both years.

Table S10 | Summary of nearest genes related to the most important QTLS identified (ripening time, RT; fruit weight, FW; and skin color, SKC).

\section{REFERENCES}

Allan, A. C., Hellens, R. P., and Laing, W. A. (2008). MYB transcription factors that colour our fruit. Trends Plant Sci. 13, 99-102. doi: 10.1016/j.tplants.2007.11.012

Ashraf, B. H., Byrne, S., Fé, D., Czaban, A., Asp, T., Pedersen, M. G., et al. (2016). Estimating genomic heritabilities at the level of progeny-pool samples of perennial ryegrass using genotyping-by-sequencing. Theor. Appl. Genet. 129, 45-52. doi: 10.1007/s00122-015-2607-9

Bajgain, P., Rouse, M. N., Tsilo, T. J., Macharia, G. K., Bhavani, S., Jin, Y., et al. (2016). Nested association mapping of stem rust resistance in wheat using genotyping by sequencing. PLOS ONE 11:e0155760. doi: 10.1371/journal.pone.0155760

Ban, Y., Honda, C., Hatsuyama, Y., Igarashi, M., Bessho, H., and Moriguchi, T. (2007). Isolation and functional analysis of a MYB transcription factor gene that is a key regulator for the development of red coloration in apple skin. Plant. Cell. Physiol. 48, 958-970. doi: 10.1093/pcp/pcm066

Bielenberg, D. G., Rauh, B., Fan, S., Gasic, K., Abbott, A. G., Reighard, G. L., et al. (2015). Genotyping by sequencing for SNP-based linkage map construction and QTL analysis of chilling requirement and bloom date in peach [Prunus persica (L.) Batsch]. PLoS ONE 10:e0139406. doi: 10.1371/journal.pone.0139406

Campoy, J. A., Le Dantec, L., Barreneche, T., Dirlewanger, E., and Quero-García, J. (2015). New insights into fruit firmness and weight control in sweet cherry. Plant. Mol. Biol. Rep. 33, 783-796. doi: 10.1007/s11105-014-0773-6

Campoy, J. A., Ruiz, D., Egea, J., Rees, D. J. G., Celton, J. M., and Martínez-Gómez, P. (2010). Inheritance of flowering time in apricot (Prunus armeniaca L.) and analysis of linked quantitative trait loci (QTLs) using simple sequence repeat (SSR) markers. Plant. Mol. Biol. Rep. 29, 404-410. doi: 10.1007/s11105-010-0242-9

Cantín, C. M., Crisosto, C. H., Ogundiwin, E. A., Gradziel, T., Torrents, J., Moreno, M. A., et al. (2010). Chilling injury susceptibility in an intra-specific peach [Prunus persica (L.) Batsch] progeny. Postharvest Biol. Technol. 58, 79-87. doi: 10.1016/j.postharvbio.2010.06.002

Castède, S., Campoy, J. A., Le Dantec, L., Quero-García, J., Barreneche, T., Wenden, B., et al. (2015). Mapping of candidate genes involved in bud dormancy and flowering time in sweet cherry (Prunus avium). PLoS ONE 10:e0143250. doi: 10.1371/journal.pone.0143250

Chagné, D., Carlisle, C. M., Blond, C., Volz, R. K., Whitworth, C. J., Oraguzie, N. C., et al. (2007). Mapping a candidate gene (MdMYB10) for red flesh and foliage colour in apple. BMC Gen. 8:212. doi: 10.1186/1471-2164-8-212

Claverie, M., Bosselut, N., Lecouls, A. C., Voisin, R., Lafargue, B., Poizat, C., et al. (2004). Location of independent root-knot nematode resistance genes in plum and peach. Theor. Appl. Genet. 108, 765-773. doi: 10.1007/s00122-003-1463-1

Contador, L., Días, M., Millanao, M., Hernández, P., Shinya, C., Sáenz, R., et al. (2016). A proposal for determining the flesh softening of peach and nectarine in postharvest through simplified targeted modeling. Sci. Hortic. 19, 47-52. doi: 10.1016/j.scienta.2016.06.015

Da Silva Linge, C., Bassi, D., Bianco, L., Pacheco, I., Pirona, R., and Rossini, L. (2015). Genetic dissection of fruit weight and size in an F2 peach (Prunus persica (L.) Batsch) progeny. Mol. Breed. 35:71. doi: 10.1007/s11032-0150271-z

De Franceschi, P., Stegmeir, T., Cabrera, A., van der Knaap, E., Rosyara, U. R., Sebolt, A. M., et al. (2013). Cell number regulator genes in Prunus provide candidate genes for the control of fruit size in sweet and sour cherry. Mol. Breed. 32, 311-326. doi: 10.1007/s11032-013-9872-6

Desnoues, E., Baldazzi, V., Génard, M., Mauroux, J. B., Lambert, P., Confolent, C., et al. (2016). Dynamic QTLs for sugars and enzyme activities provide an overview of genetic control of sugar metabolism during peach fruit development. J. Exp. Bot. 67, 1-13. doi: 10.1093/jxb/erw169

Dirlewanger, E., Cosson, P., Howad, W., Capdeville, G., Bosselut, N., Claverie, M., et al. (2004a). Microsatellite genetic linkage maps of myrobalan plum and an almond-peach hybrid - Location of root-knot nematode resistance genes. Theor. Appl. Genet. 109, 827-838. doi: 10.1007/s00122-004-1694-9

Dirlewanger, E., Graziano, E., Joobeur, T., Garriga-Caldere, F., Cosson, P., Howad, W., et al. (2004b). Comparative mapping and marker assisted selection in Rosaceae fruit crops. Proc. Natl. Acad. Sci. U.S.A. 101, 9891-9896. doi: 10.1073/pnas.0307937101

Dirlewanger, E., Moing, A., Rothan, C., Svanella, L., Pronier, V., Guye, A., et al. (1999). Mapping QTLs controlling fruit quality in peach (Prunus persica (L.) Batsch). Theor. Appl. Genet. 98, 18-31. doi: 10.1007/s001220051035

Dirlewanger, E., Quero-García, J., Le Dantec, L., Lambert, P., Ruiz, D., Dondini, L., et al. (2012). Comparison of the genetic determinism of two key phenological traits, flowering and maturity dates, in three Prunus species: peach, apricot and sweet cherry. Heredity 109, 280-292. doi: 10.1038/hdy.2012.38

Doyle, J. J., and Doyle, J. L. (1987). A rapid isolation procedure for small quantities of fresh leaf tissue. Phytochem. Bull. 19, 11-15.

Eduardo, I., Pacheco, I., Chietera, G., Bassi, D., Pozzi, C., Vecchietti, A., et al. (2011). QTL analysis of fruit quality traits in two peach intraspecific populations and importance of maturity date pleiotropic effect. Tree Genet. Gen. 7, 323-335. doi: 10.1007/s11295-010-0334-6

Eduardo, I., Picañol, R., Rojas, E., Batlle, I., Howad, W., Aranzana, M. J., et al. (2015). Mapping of a major gene for the slow ripening character in peach: co-location with the maturity date gene and development of a candidate gene-based diagnostic marker for its selection. Euphytica 205, 627-636. doi: 10.1007/s10681-015-1445-9

Elshire, R. J., Glaubitz, J. C., Sun, Q., Poland, J. A., Kawamoto, K., Buckler, E. S., et al. (2011). A robust, simple genotyping-by-sequencing (GBS) approach for high diversity species. PLOS ONE 6:e19379. doi: 10.1371/journal.pone.00 19379

Etienne, C., Rothan, C., Moing, A., Plomion, C., Svanella-Dumas, L., and Dirlewanger, E. (2002). Candidate genes and QTLs for sugar and organic acid content in peach [Prunus persica (L.) Batsch]. Theor. Appl. Genet. 105, 145-159. doi: 10.1007/s00122-001-0841-9 
Frary, A., Nesbitt, T. C., Frary, A., Grandillo, S., van der Knaap, E., Cong, B., et al. (2000). fw2.2: a quantitative trait locus key to the evolution of tomato fruit size. Science 289, 85-88. doi: 10.1126/science.289.5476.85

Fresnedo-Ramírez, J., Bink, M. C., van de Weg, E., Famula, T. R., Crisosto, C. H., Frett, T. J., et al. (2015). QTL mapping of pomological traits in peach and related species breeding germplasm. Mol. Breed. 35, 1-19. doi: $10.1007 /$ s11032-015-0357-7

Fresnedo-Ramírez, J., Frett, T. J., Sandefur, P. J., Salgado-Rojas, A., Clark, J. R., Gasic, K., et al. (2016). QTL mapping and breeding value estimation through pedigree-based analysis of fruit size and weight in four diverse peach breeding programs. Tree Genet. Gen. 12:25. doi: 10.1007/s11295-0160985-Z

Frett, T. J., Reighard, G. L., Okie, W. R., and Gasic, K. (2014). Mapping quantitative trait loci associated with blush in peach [Prunus persica (L.) Batsch]. Tree Genet. Gen. 10, 367-381. doi: 10.1007/s11295-013-0692-y

González, M., Salazar, E., Morales, J. C. P., Mura-Jornet, J., Maldonado, J., Silva, H., et al. (2016). Genetic structure based on EST-SSR: a putative tool for fruit color selection in Japanese plum (Prunus salicina L.) breeding programs. Mol. Breed. 36:68. doi: 10.1007/s11032-016-0491-x

Gottardi, F., Noferini, M., Fiori, G., Barbanera, M., Mazzini, C., and Costa, G. (2009). "The index of absorbance difference (IAD) as a tool for segregating peaches and nectarines into homogeneous classes with different shelf-life and consumer acceptance," in Proceedings of the 8th Pangborn Sensory Science Symposium. Firenze.

Guajardo, V., Solís, S., Sagredo, B., Gainza, F., Muñoz, C., Gasic, K., et al. (2015). Construction of high density sweet cherry (Prunus avium L.) linkage maps using microsatellite markers and SNPs detected by genotyping-by-sequencing (GBS). PLoS ONE 10:e0127750. doi: 10.1371/journal.pone.0127750

Guo, M., Rupe, M. A., Dieter, J. A., Zou, J., Spielbauer, D., Duncan, K. E., et al. (2010). Cell number regulator 1 affects plant and organ size in maize: implications for crop yield enhancement and heterosis. Plant Cell 22, 1057-1073. doi: 10.1105/tpc. 109.073676

Hartmann, W., and Neumüller, M. (2009). "Plum breeding," in Breeding Plantation Tree Crops: Temperate Species, eds S. M. Jain and P. M. Priyadarshan (New York, NY: Springer), 161-231.

Illa, E., Eduardo, I., Audergon, J. M., Barale, F., Dirlewanger, E., Li, X., et al. (2011). Saturating the Prunus (stone fruits) genome with candidate genes for fruit quality. Mol. Breed. 28, 667-682. doi: 10.1007/s11032-010-9518-x

Infante, R., Contador, L., Rubio, P., Mesa, K., and Meneses, C. (2011b). Nondestructive monitoring of flesh softening in the black-skinned Japanese plums "Angeleno" and "Autumn beaut" on-tree and postharvest. Postharvest Biol. Technol. 61, 35-40. doi: 10.1016/j.postharvbio.2011.01.003

Infante, R., Rubio, P., Contador, L., Noferini, M., and Costa, G. (2011a). Determination of harvest maturity of D'Agen plums using the chlorophyll absorbance index. Ciencia Investigación Agraria 38, 199-203. doi: 10.4067/S0718-16202011000200004

Lambert, P., Campoy, J. A., Pacheco, I., Mauroux, J. B., Da Silva Linge, C., Micheletti, D., et al. (2016). Identifying SNP markers tightly associated with six major genes in peach [Prunus persica (L.) Batsch] using a high-density SNP array with an objective of marker-assisted selection (MAS). Tree Genet. Gen. 12:121. doi: 10.1007/s11295-016-1080-1

Lee, J., Izzah, N. K., Choi, B. S., Joh, H. J., Lee, S. C., Perumal, S., et al. (2015). Genotyping-by-sequencing map permits identification of clubroot resistance QTLs and revision of the reference genome assembly in cabbage (Brassica oleracea L.). DNA Res. 23, 29-41. doi: 10.1093/dnares/dsv034

Lin, M., Cai, S., Wang, S., Liu, S., Zhang, G., and Bai, G. (2015). Genotyping-by-sequencing (GBS) identified SNP tightly linked to QTL for pre-harvest sprouting resistance. Theor. Appl. Genet. 128, 1385-1395. doi: 10.1007/s00122-015-2513-1

Liu, W., Liu, N., Yu, X., Sun, M., Zhang, Y., Xu, M., et al. (2013). Plum germplasm resources and breeding in liaoning of China. Acta Hortic. 985, 43-46. doi: 10.17660/ActaHortic.2013.985.4

Martínez-García, P. J., Fresnedo-Ramírez, J., Parfitt, D. E., Gradziel, T. M., and Crisosto, C. H. (2013b). Effect prediction of identified SNPs linked to fruit quality and chilling injury in peach [Prunus persica (L.) Batsch]. Plant Mol. Biol. 81, 161-174. doi: 10.1007/s11103-012-9989-8

Martínez-García, P. J., Parfitt, D. E., Bostock, R. M., Fresnedo-Ramírez, J., Vazquez-Lobo, A., Ogundiwin, E. A., et al. (2013a). Application of genomic and quantitative genetic tools to identify candidate resistance genes for brown rot resistance in peach. PLoS ONE 8:e78634. doi: 10.1371/journal.pone.0078634

McAllister, C. A., and Miller, A. J. (2016). Single nucleotide polymorphism discovery via genotyping by sequencing to assess population genetic structure and recurrent polyploidization in Andropogon gerardii. Am. J. Bot. 103, 1314-1325. doi: 10.3732/ajb.1600146

Nuñez-Lillo, G., Cifuentes-Esquivel, A., Troggio, M., Micheletti, D., Infante, R., Campos-Vargas, R., et al. (2015). Identification of candidate genes associated with mealiness and maturity date in peach [Prunus persica (L.) Batsch] using QTL analysis and deep sequencing. Tree Genet. Gen. 11:86. doi: 10.1007/s11295-015-0911-9

Okie, W. R., and Ramming, D. W. (1999). Plum breeding worldwide. Hortic. Technol. 9, 162-176.

Pacheco, I., Bassi, D., Eduardo, I., Ciacciulli, A., Pirona, R., Rossini, L., et al. (2014). QTL mapping for brown rot (Monilinia fructigena) tolerance in an intraspecific peach (Prunus persica L. Batsch) F1 progeny. Tree Genet. Genomes 10, 1223-1242. doi: 10.1007/s11295-014-0756-7

Pirona, R., Eduardo, I., Pacheco, I., Da Silva Linge, C., Miculan, M., Verde, I., et al. (2013). Fine mapping and identification of a candidate gene for a major locus controlling maturity date in peach. BMC. Plant. Biol. 13:166. doi: 10.1186/1471-2229-13-166

Quarta, R., Dettori, M. T., Sartori, A., and Verde, I. (2000). Genetic linkage map and QTL analysis in peach. Acta. Hortic. 521, 233-241. doi: 10.17660/ActaHortic.2000.521.26

Quilot, B., Wu, B. H., Kervella, J., Génard, M., Foulongne, M., and Moreau, K. (2004). QTL analysis of quality traits in an advanced backcross between Prunus persica genotypes and the wild relative species $P$. davidiana. Theor. Appl. Genet. 109, 884-897. doi: 10.1007/s00122-004-1703-Z

Rabbi, I. Y., Kulakow, P. A., Manu-Aduening, J. A., Dankyi, A. A., Asibuo, J. Y., Parkes, E. Y., et al. (2015). Tracking crop varieties using genotyping-bysequencing markers: a case study using cassava (Manihot esculenta Crantz). BMC. Genet. 16:115. doi: 10.1186/s12863-015-0273-1

Rosyara, U. R., Bink, M. C. A. M., van de Weg, E., Zhang, G., Wang, D., Sebolt, A., et al. (2013). Fruit size QTL identification and the prediction of parental QTL genotypes and breeding values in multiple pedigreed populations of sweet cherry. Mol. Breed. 32, 875-887. doi: 10.1007/s11032-013-9916-y

Ruiz, D., Egea, J., Guevara, A., García, F., Carrillo, A., Nortes, M. D., et al. (2016). "Progress in the Japanese plum (Prunus salicina L.) breeding program developed by CEBAS-CSIC and IMIDA in Murcia (Spain)," in Proceeding of the XI International Symposium on Plum and Prune Genetics. Breeding and Pomology. Freising.

Ruiz, D., Lambert, P., Audergon, J. M., Dondini, L., Tartarini, S., Adami, M., et al. (2010). Identification of QTLs for fruit quality traits in apricot. Acta. Hortic. 862, 587-592. doi: 10.17660/ActaHortic.2010.862.93

Salazar, J. A., Ruiz, D., Campoy, J. A., Sánchez-Pérez, R., Crisosto, C. H., MartínezGarcía, P. J., et al. (2014). Quantitative trait loci (QTL) and mendelian trait loci (MTL) analysis in Prunus: a breeding perspective and beyond. Plant. Mol. Biol. Rep. 32, 1-18. doi: 10.1007/s11105-013-0643-7

Salazar, J. A., Ruiz, D., Campoy, J. A., Tartarini, S., Dondini, L., and Martínez-Gómez, P. (2016). Inheritance of reproductive phenology traits and related QTL identification in apricot. Tree Genet. Gen. 12:71. doi: 10.1007/s11295-016-1027-6

Salazar, J. A., Ruiz, D., Egea, J., and Martínez-Gómez, P. (2013). Transmission of fruit quality traits in apricot (Prunus armeniaca L.) and analysis of linked quantitative trait loci (QTLs) using simple sequence repeat (SSR) markers. Plant. Mol. Biol. Rep. 31, 1506-1517. doi: 10.1007/s11105-013-0625-9

Shen, J., Lv, B., Luo, L., He, J., Mao, C., Xi, D., et al. (2017). The NAC-type transcription factor OsNAC2 regulates ABA-dependent genes and abiotic stress tolerance in rice. Sci. Rep. 7:40641. doi: 10.1038/srep40641

Singh, S. P., Singh, Z., and Swinny, E. E. (2012). Climacteric level during fruit ripening influences lipid peroxidation and enzymatic and non-enzymatic antioxidative systems in Japanese plums (Prunus salicina Lindell). Postharvest Biol. Technol. 65, 22-32. doi: 10.1016/j.postharvbio.2011.10.007

Socquet-Juglard, D., Christen, D., Devignes, G., Gessler, C., Duffy, B., and Patocchi, A. (2013). Mapping, architectural, phenological, and fruit quality QTLs in apricot. Plant Mol. Biol. Rep. 31, 387-397. doi: 10.1007/s11105-012-0511-x

Sooriyapathirana, S. S., Khan, A., Sebolt, A. M., Wang, D., Bushakra, J. M., LinWang, K., et al. (2010). QTL analysis and candidate gene mapping for skin and 
flesh color in sweet cherry fruit (Prunus avium L.). Tree Genet. Gen. 6, 821-832. doi: 10.1007/s11295-010-0294-x

Takos, A. M., Jaffe, F. W., Jacob, S. R., Bogs, J., Robinson, S. P., and Walker, A. R. (2006). Light-induced expression of a MYB gene regulates anthocyanin biosynthesis in red apples. Plant. Physiol. 142, 1216-1232. doi: 10.1104/pp.106.088104

Topp, B. L., Russell, D. M., Neumüller, M., Dalbó, M. A., and Liu, W. (2012). "Plum," in Fruit Breeding, Handbook of Plant Breeding, Vol. 8, eds M. L. Badenes and D. H. Byrne (New York, NY: Springer), 571-621.

Van Ghelder, C., Lafargue, B., Dirlewanger, E., Oussa, A., Voisin, R., Polidori, J., et al. (2010). Characterization of the RMja gene for resistance to root-knot nematodes in almond: spectrum, location, and interest for Prunus breeding. Tree Genet. Gen. 6, 503-511. doi: 10.1007/s11295-010-0268-z

Van Ooijen, J. W. (2006). JoinMap 4, Software for the Calculation of Genetic Linkage Maps in Experimental Populations. Wageningen: Kyazma. BV.

Verde, I., Abbott, A. G., Scalabrin, S., Jung, S., Shu, S., Marroni, F., et al. (2013). The high-quality draft genome of peach (Prunus persica) identifies unique patterns of genetic diversity, domestication and genome evolution. Nat. Genet. 45, 487-494. doi: 10.1038/ng.2586

Verde, I., Bassil, N., Scalabrin, S., Gilmore, B., Lawley, C. T., Gasic, K., et al. (2012). Development and evaluation of a 9K SNParray for peach by internationally coordinated SNP detection and validation in breeding germplasm. PLoS ONE 7:e35668. doi: 10.1371/journal.pone.0035668

Verde, I., Quarta, R., Cedrola, C., and Dettori, M. T. (2002). QTL analysis of agronomic traits in a BC1 peach population. Acta Hortic. 592, 291-297. doi: 10.17660/ActaHortic.2002.592.41

Verma, S., Gupta, S., Bandhiwal, N., Kumar, T., Bharadwaj, C., and Bhatia, S. (2015). High-density linkage map construction and mapping of seed trait QTLs in chickpea (Cicer arietinum L.) using genotyping-by-sequencing (GBS). Sci. Rep. 5:17512. doi: 10.1038/srep17512

Voorrips, R. E. (2002). MapChart: software for the graphical presentation of linkage maps and QTLs. J. Heredity 93, 77-78. doi: 10.1093/jhered/93.1.77
Wu, F., Zhang, D., Zhang, H., Jiang, G., Su, X., Qu, H., et al. (2011). Physiological and biochemical response of harvested plum fruit to oxalic acid during ripening or shelf-life. Food. Res. Int. 44, 1299-1305. doi: 10.1016/j.foodres.2010. 12.027

Yang, N., Reighard, G., Ritchie, D., Okie, W., and Gasic, K. (2013). Mapping quantitative trait loci associated with resistance to bacterial spot (Xanthomonas arboricola pv. pruni) in peach. Tree Genet. Gen. 9, 573-586. doi: 10.1007/s11295-012-0580-x

Yang, S., Fresnedo-Ramírez, J., Wang, M., Cote, L., Schweitzer, P., Barba, P., et al. (2016). A next-generation marker genotyping platform (AmpSeq) in heterozygous crops: a case study for marker-assisted selection in grapevine. Hortic. Res. 3:16002. doi: 10.1038/hortres.2016.2

Zeballos, J. L., Abidi, W., Giménez, S., Monforte, A. J., Moreno, M. A., and Gogorcena, Y. (2016). Mapping QTLs associated with fruit quality traits in peach [Prunus persica (L.) Batsch] using SNP maps. Tree Genet. Gen. 12:3. doi: 10.1007/s11295-016-0996-9

Zhang, G., Sebolt, A. M., Sooriyapathirana, S. S., Wang, D., Bink, M. C., Olmstead, J. W., et al. (2010). Fruit size QTL analysis of an F1 population derived from a cross between a domesticated sweet cherry genotype and a wild forest sweet cherry. Tree Genet. Gen. 6, 25-36. doi: 10.1007/s11295-009-0225-x

Conflict of Interest Statement: The authors declare that the research was conducted in the absence of any commercial or financial relationships that could be construed as a potential conflict of interest.

Copyright $\odot 2017$ Salazar, Pacheco, Shinya, Zapata, Silva, Aradhya, Velasco, Ruiz, Martinez-Gómez and Infante. This is an open-access article distributed under the terms of the Creative Commons Attribution License (CC BY). The use, distribution or reproduction in other forums is permitted, provided the original author(s) or licensor are credited and that the original publication in this journal is cited, in accordance with accepted academic practice. No use, distribution or reproduction is permitted which does not comply with these terms. 